\title{
O serialismo de Camargo Guarnieri no seu Concerto para Piano e Orquestra N. 5
}

\author{
Liduino Pitombeira (UFPB, João Pessoa) \\ pitombeira@yahoo.com
}

Resumo. Camargo Guarnieri, que com tanta firmeza lutou contra o estabelecimento do serialismo no Brasil, na década de 1950, posteriormente utilizou estruturas atonais e procedimentos seriais. Este artigo demonstra a utilização de atonalismo e serialismo no Concerto para Piano e Orquestra N. ${ }^{\circ}$, através da análise da exposição de seu primeiro movimento. $\mathrm{Na}$ análise, definiu-se um sistema classificatório para as cinco sonoridades atonais utilizadas no concerto, tomando como referência a teoria dos conjuntos de classes-de-notas (FORTE, 1973).

Palavras-chave: Camargo Guarnieri, Concerto N $\circ 5$ para Piano, serialismo, atonalismo.

\section{The serialism of Camargo Guarnieri in his Fifth Piano Concerto}

Abstract. Brazilian composer Camargo Guarnieri, who firmly fought against the establishment of serialism in Brazil in the 1950s, later employed atonal structures and serial procedures. This article aims at demonstrating the use of atonalism and serialism in his Fifth Concerto for Piano and Orchestra, through the analysis of its first movement's exposition. In the analysis, a system of classification for the five sonorities found in the piece was defined using pitchclass set theory (FORTE, 1973) as a reference.

Keywords: Camargo Guarnieri, Fifth Piano Concerto, serialism, atonalism.

\section{1 - Considerações históricas e estruturais}

Camargo Guarnieri (1907-1993) compôs dez obras para piano e orquestra, incluindo seis concertos. ${ }^{1} 0$ Concerto para Piano e Orquestra $N .^{\circ} 5$ foi encomendado pelo Jornal do Brasil, para ter primeira audição durante o II Festival de Música da Guanabara. Com vinte e três minutos de duração, esta obra foi composta no curto período de um mês (janeiro de 1970), quando Guarnieri ensinava na Universidade Federal de Goiânia. A primeira audição foi realizada pela pianista Laís de Souza Brasil, a quem a obra foi dedicada, em maio do mesmo ano. Em 1973, a obra teve sua primeira audição no exterior, com a mesma pianista e com Guarnieri regendo a Chicago Symphony Orchestra.

A obra tem três movimentos: Improvisando, Sideral e Jocoso. 0 primeiro movimento, único que será comentado na análise, é na forma allegro de sonata, o segundo é um $A B A$ monotemático e o terceiro é na forma rondó em forma de arco (arch form) ABCBA (VERHAALEN, 2001, p.232). ${ }^{2}$ A obra é inteiramente construída a partir do gesto mostrado no Ex.1, o qual consiste em uma sétima maior ascendente, duas segundas menores descendentes e uma terça menor descendente. Este motivo de cinco notas, manipulado tanto de forma ordenada como desordenada, ${ }^{3}$ é utilizado ciclicamente na obra, isto é, aparece nos três movimentos, não somente como um motivo de natureza melódica, mas também como estrutura geradora da linguagem harmônica. Assim sendo, as sonoridades de sétima maior (primeiro intervalo), segunda menor (segundo e terceiro intervalos), bem como harmonia quartal (intervalo entre a segunda e última notas) derivam deste gesto gerador. Este motivo é enunciado logo no início do concerto pela orquestra e é sistematicamente elaborado, tanto pelo piano como pela orquestra durante toda a peça, até o seu último compasso.

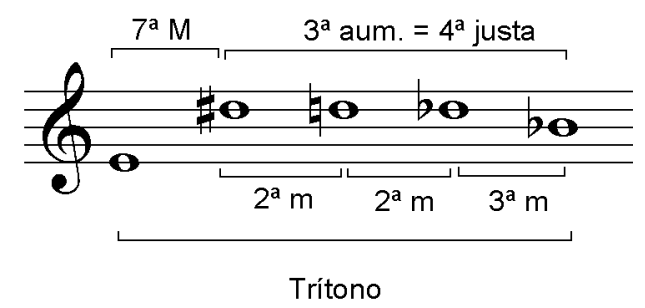

Ex.1 - Gesto gerador do Concerto para Piano e Orquestra N. 5 de Camargo Guarnieri 


\section{2 - Classificação dos tipos de sonoridade utilizados na análise}

Uma vez que a linguagem harmônica da obra não utiliza nem o vocabulário nem a sintaxe tonais, introduzir-se-á um conjunto de cinco tipos de sonoridades, detectados em uma fase inicial prospectiva, e definidos aqui como objetos contendo dois ou mais intervalos melódicos e/ou harmônicos desordenados e construídos a partir dos seguintes princípios, inspirados em FORTE (1973): ${ }^{4}$

1 Princípio da Equivalência Enarmônica: intervalos enarmônicos são considerados equivalentes. Portanto, um segunda aumentada é equivalente a uma terça diminuta, por exemplo.
2 Princípio da Equivalência de Oitava: de acordo com este princípio, Dó $=$ Dó $_{0}=$ Dó $_{1}=$ Dó $_{2} \mathrm{e}_{1}$ assim, sucessivamente (neste artigo, Dó é o Dó central do piano).

3 Princípio da Equivalência Inversional: conseqüência direta do princípio de equivalência de oitava. De acordo com este princípio, o intervalo criado pelo deslocamento de oitava de um de seus componentes é taxionomicamente equivalente ao próprio intervalo original. Este princípio se aplica também para intervalos compostos. Assim sendo, por exemplo, uma quinta justa é equivalente a uma quarta justa, já que a diferença entre estes dois intervalos só existe em virtude do deslocamento de oitava de uma das notas destes intervalos. 0 quadro abaixo (Ex.2 a 6) descreve os tipos de sonoridades utilizados na análise.

Exs.2 a 6 - Quadro de tipos de sonoridades utilizados na análise

\begin{tabular}{|c|c|}
\hline EXEMPLO & DESCRIÇÃO \\
\hline  & $\begin{array}{l}\text { Tipo 1: tricorde contendo os seguintes intervalos, ou } \\
\text { seus equivalentes: trítono, quarta justa (ou quinta } \\
\text { justa) e sétima maior (ou segunda menor). Esta } \\
\text { sonoridade corresponde à primeira, à mais aguda e } \\
\text { à última nota do gesto gerador. Também pertence } \\
\text { ao Tipo 1, um tetracorde cujos tricordes sejam todos } \\
\text { do Tipo 1, por exemplo: Dó-Dó\#-Fá\#-Sol. }\end{array}$ \\
\hline  & $\begin{array}{l}\text { Tipo 2a: tricorde contendo duas quartas justas } \\
\text { consecutivas ou dois intervalos que possam } \\
\text { ser arranjados em quartas justas através de } \\
\text { deslocamentos de oitava. Esta sonoridade se } \\
\text { relaciona com harmonia quartal, que é utilizada } \\
\text { abundantemente por Guarnieri nesta obra. Se o } \\
\text { conjunto tiver mais do que três quartas justas será } \\
\text { denominado Tipo } 2 b \text {. }\end{array}$ \\
\hline $\begin{array}{l}\text { Ex.4 - Geração do Tipo } 3 \\
\text { Tipo } 1 \\
\end{array}$ & $\begin{array}{l}\text { Comparando as relações intervalares entre os Tipos } \\
1 \text { e } 2 \text { observa-se que o Tipo } 2 \text { pode ser considerado } \\
\text { como uma contração do Tipo } 1 \text {. Observa-se, na } \\
\text { figura 4, que, se o Dó permanecer como centro } \\
\text { referencial, o Tipo } 1 \text { é transformado no Tipo } 2 \\
\text { através da transposição das outras duas classes-de- } \\
\text { notas uma segunda menor descendentemente. A } \\
\text { continuação deste processo resultará na definição } \\
\text { dos Tipos } 3 a \text { (tríade menor) e } 3 b \text { (tríade maior). }\end{array}$ \\
\hline $\begin{array}{l}\text { Ex.5 - Tipo } 4 \\
\frac{0}{70} \mathbf{0}\end{array}$ & $\begin{array}{l}\text { O Tipo } 4 \text { também é derivado do motivo de } \\
\text { cinco notas. É formado por segundas meno- } \\
\text { res (ou intervalos equivalentes), em qualquer } \\
\text { quantidade. }\end{array}$ \\
\hline 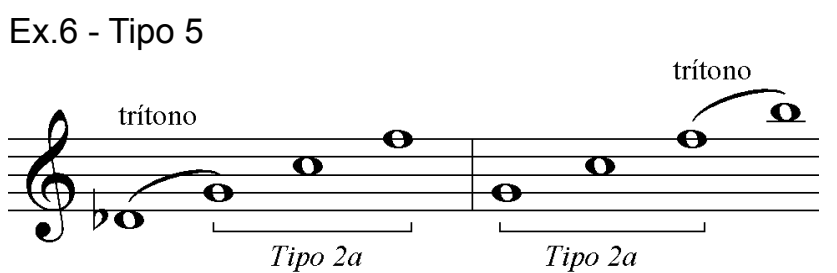 & $\begin{array}{l}\text { O Tipo } 5 \text { é construído pela adição de um trí- } \\
\text { tono a uma das extremidades de um tricorde } \\
\text { quartal, disposto em quartas (Tipo } 2 a \text { ). }\end{array}$ \\
\hline
\end{tabular}




\section{3 - Análise da exposição do Primeiro Movimento: "Improvisando"}

0 compositor prepara a entrada do primeiro tema com três eventos introdutórios, cada um com caráter distinto. Uma redução do primeiro evento, o qual é executado somente pela orquestra, é mostrada no Ex. $7^{5}$ Observase uma textura densa produzida pela justaposição dos Tipos 1, 2 e 5. Os instrumentos mais graves executam claramente o motivo de cinco notas, que é o gesto gerador da obra. Seguindo-se a esta 'explosão' orquestral, ocorre um momento de silêncio, de onde surge o piano executando uma cadência (Ex.8), cujo material é inteiramente construído com os Tipos $2 a$ e $5 .{ }^{6} 0$ último evento introdutório consiste em um cânon à quinta, a três vozes, construído exclusivamente com o motivo de cinco notas, executado pelos metais e acompanhado por um prato suspenso e por segundas menores executadas pelas cordas agudas, com o objetivo de criar ressonância (Ex.9). A este cânon segue-se o primeiro tema, executado somente pelo piano.

Poder-se-ia afirmar que o primeiro tema do concerto é apresentado logo no início da obra. Neste caso, a segunda entrada do piano seria uma reexposição do tema, uma vez que também é totalmente baseada no motivo de cinco notas. Este recurso, isto é, a exposição do tema pela orquestra e subsequentemente pelo piano, é chamado de exposição dupla e é tradicionalmente usado nos concertos clássicos. No entanto, propõe-se, neste estudo, que o motivo de cinco notas é introduzido no início ainda como material primitivo (embora tenha alturas, ritmos, dinâmicas e articulações bem definidas), tendo mesmo 0

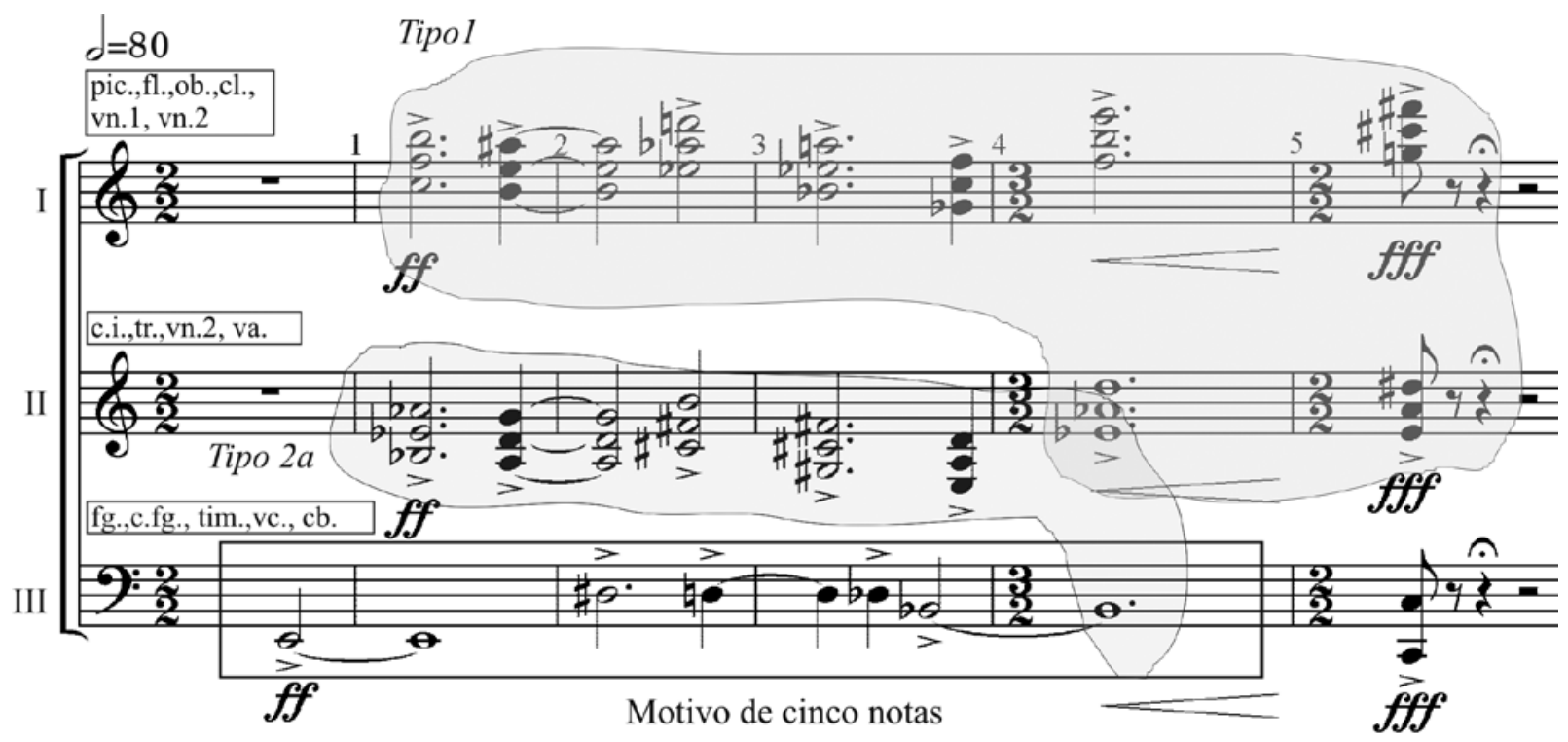

Ex.7 - Redução da abertura orquestral do Concerto para Piano e Orquestra N. ${ }^{\circ} 5$ de Camargo Guarnieri

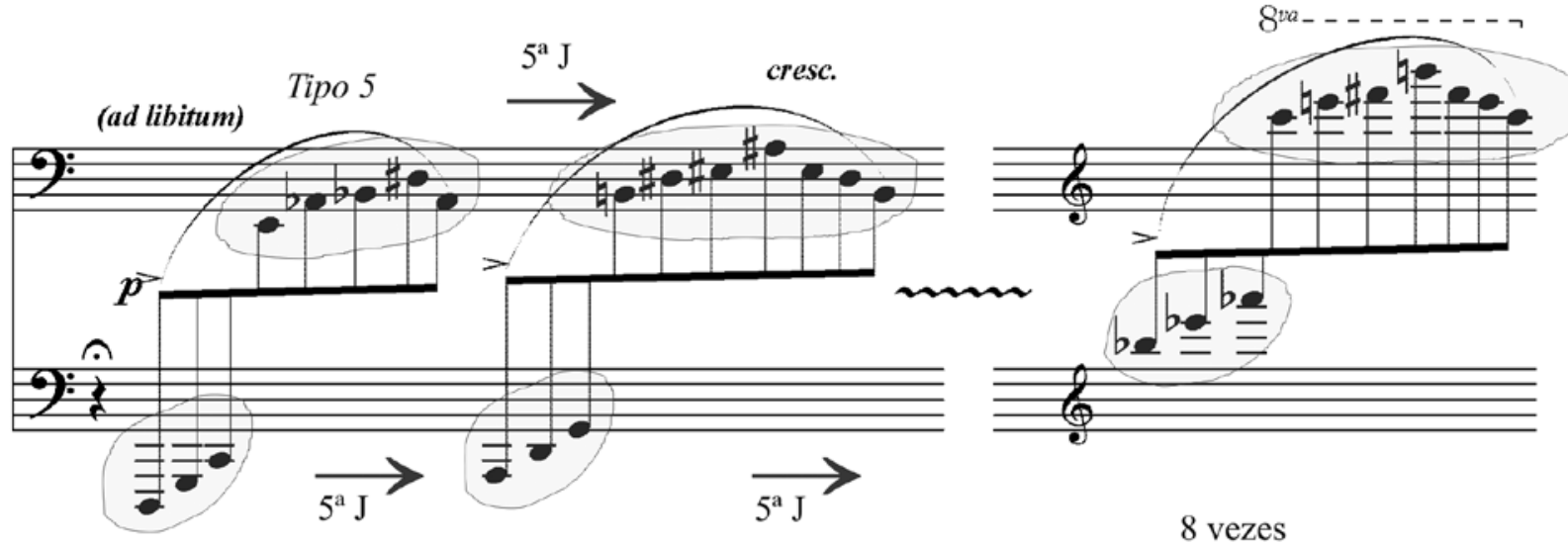

Tipo 2 a

Ex.8 - Cadência do piano do Concerto para Piano e Orquestra N. 5 de Camargo Guarnieri 


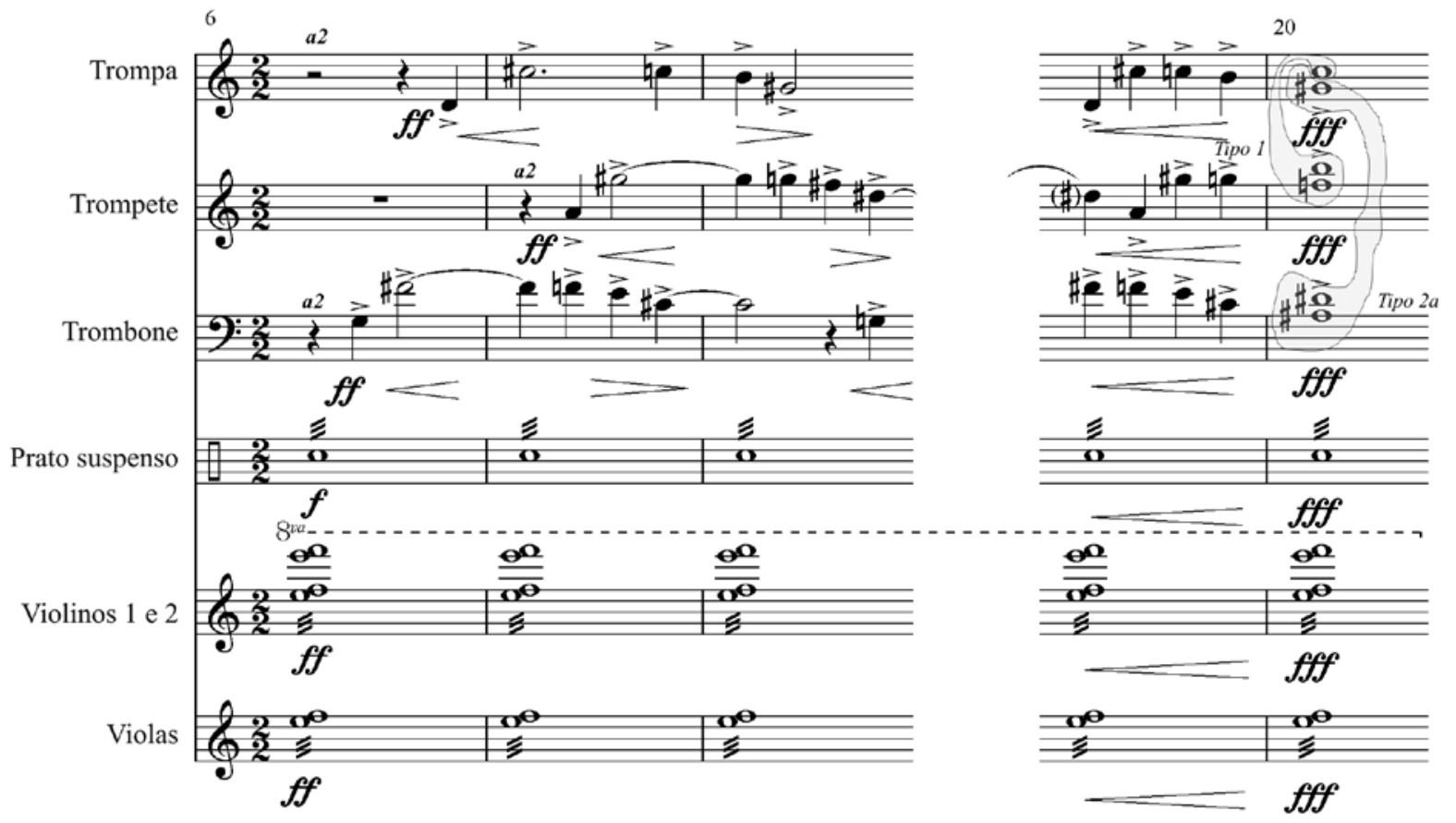

Ex.9 - Cânon dos metais do Concerto para Piano e Orquestra N. 5 de Camargo Guarnieri
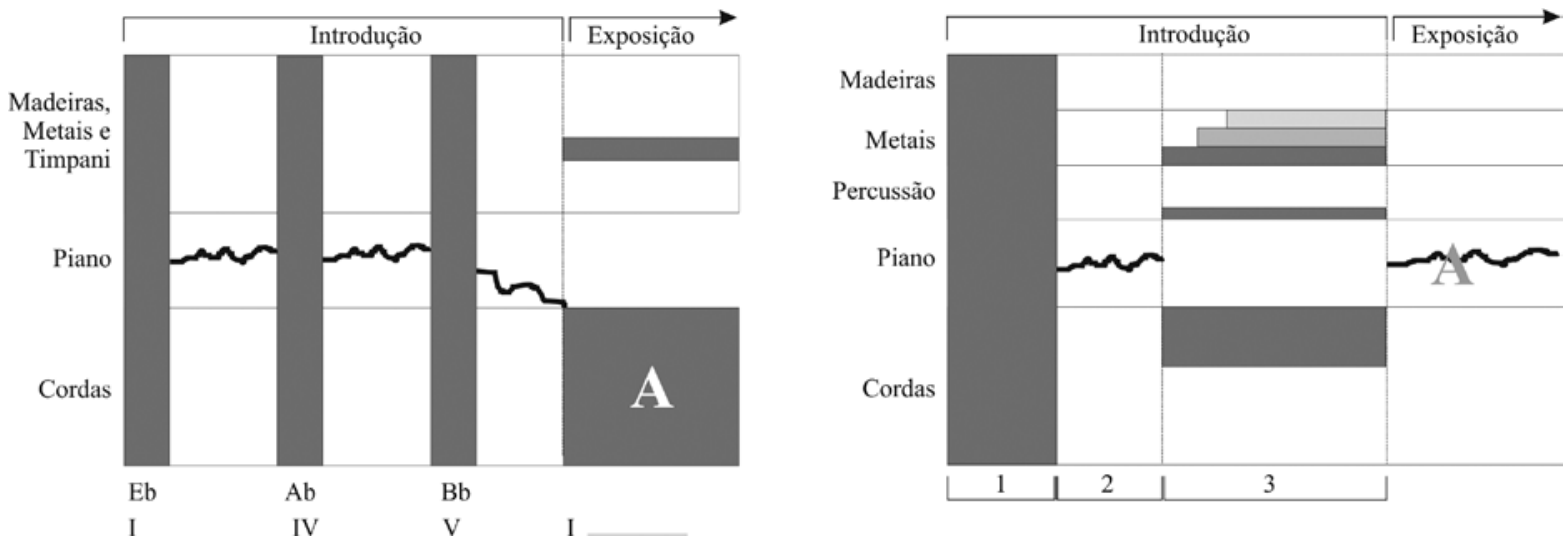

Ex.10 - Diagrama das introduções do Concerto para Piano e Orquestra N. 5 de Beethoven (esquerda) e do Concerto para Piano e Orquestra N. ${ }^{\circ} 5$ de Camargo Guarnieri (direita)

caráter de arquétipo, de célula geradora inicial de onde toda a obra vai brotar. Considera-se que, mesmo a obra não sendo tonal, Guarnieri, por sua forte ligação com a tradição, precisava estabelecer uma atmosfera sonora, falando metaforicamente, antes que os temas pudessem ser apresentados e desenvolvidos. ${ }^{7}$ Leve-se em conta, ainda, que esta obra não é dodecafônica nem utiliza serialismo integral, técnicas que permitem conexões literais entre materiais temáticos e arquétipos geradores. Desta forma, considera-se que o motivo de cinco notas, em um primeiro momento funciona somente como um arquétipo desta nova atmosfera sonora, tendo uma função análoga a uma introdução ou um prelúdio de uma obra tonal.
Buscando este paralelo com o repertório tonal, examinemos brevemente a abertura do Concerto para Piano e Orquestra $N .^{\circ} 5$ de Beethoven. Esta obra inicia-se com um acorde de tônica (Mi bemol maior) executado pela orquestra, ao qual se seguem uma série de arpejos tocados livremente pelo piano, quase como uma cadência. Este mesmo procedimento é repetido mais duas vezes, uma para a subdominante e outra para a dominante, e em seguida, a orquestra executa o primeiro tema, o qual é reexposto mais tarde pelo piano. Com este material introdutório, consistindo de três momentos, Beethoven parece estar simplesmente estabelecendo claramente a tonalidade da peça, através das funções principais. Como se pode 
observar nos diagramas do Ex.10, ambos os compositores estão introduzindo vocabulário (sonoridades) e sintaxe (como interconectar estas sonoridades), cada um dentro de uma linguagem específica, preparando o terreno para a entrada do tema propriamente dito. No caso de Beethoven, a linguagem já é o então estabelecido sistema tonal, enquanto que em Guarnieri, não somente a obra teve de ser criada, mas também o próprio sistema. Em outras palavras, enquanto Beethoven escolheu entre as várias possibilidades sintáticas já amplamente disponíveis no sistema tonal, Guarnieri teve de criar o vocabulário e uma sintaxe especifica para interconectar este vocabulário.

Os tipos de sonoridades, definidos anteriormente, são elementos desordenados. Examinemos a seguir, as possíveis disposições do motivo de cinco notas, quando considerado do ponto de vista ordenado. 0 Ex.11 mostra todas as formas ordenadas do motivo (original, inversa, retrógrada, inversão da retrógrada, todas com suas devidas transposições). ${ }^{8}$ Considerou-se $P_{0} \quad 0$ formato em que o motivo foi introduzindo no início da obra. Guarnieri também utiliza estas formas seriais de maneira desordenada, como veremos adiante.

0 Ex.12 mostra os quatro compassos iniciais da exposição do tema feita pelo piano. Os números dentro de círculos referem-se aos tipos de sonoridades. As formas seriais indicadas dentro de colchetes são formas desordenadas. Por exemplo, $\mathrm{P}_{0}$ é Mi,Ré\#,Ré,Dó\#,Lá\#, mas $\left[\mathrm{P}_{0}\right]$ indica qualquer ordem destas cinco notas. Como se observa no Ex.13, tudo é derivado do motivo gerador. Algumas vezes este motivo aparece em sua forma completa e na ordem original; noutras é desordenado, incompleto ou apresenta notas interpoladas. A interpolação de notas estranhas às formas seriais é particularmente importante na construção do primeiro tema $(A)$, porque confere variedade e dilui a rigidez sistêmica. Observa-se como Guarnieri reintroduz o motivo de cinco notas no c.21, de forma cristalina e gradualmente

\begin{tabular}{|c|c|c|c|c|c|c|}
\hline$P_{0}$ & $\mathrm{E}$ & $\mathrm{D} \#$ & $\mathrm{D}$ & $\mathrm{C \#}$ & A\# & $\mathrm{R}_{0}$ \\
\hline$P_{1}$ & $\mathrm{~F}$ & $\mathrm{E}$ & D\# & $D$ & B & $R_{1}$ \\
\hline$P_{2}$ & F\# & $\mathrm{F}$ & $\mathrm{E}$ & D\# & C & $R_{2}$ \\
\hline$P_{3}$ & G & F\# & $\mathrm{F}$ & $\mathrm{E}$ & C\# & $\mathrm{R}_{3}$ \\
\hline$P_{4}$ & $\mathrm{G} \#$ & G & F\# & $F$ & $D$ & $\mathrm{R}_{4}$ \\
\hline$P_{5}$ & $\mathrm{~A}$ & $\mathrm{G} \#$ & $\mathrm{G}$ & F\# & D\# & $R_{5}$ \\
\hline$P_{6}$ & A\# & A & $\mathrm{G} \#$ & $\mathrm{G}$ & $\mathrm{E}$ & $R_{6}$ \\
\hline$P_{7}$ & B & A\# & A & $\mathrm{G} \#$ & $\mathrm{~F}$ & $R_{7}$ \\
\hline$P_{8}$ & C & B & A\# & A & F\# & $\mathrm{R}_{8}$ \\
\hline$P_{9}$ & C\# & C & B & A\# & $\mathrm{G}$ & $R_{9}$ \\
\hline$P_{10}$ & $\mathrm{D}$ & $\mathrm{C \#}$ & C & B & $\mathrm{G} \#$ & $\mathbf{R}_{10}$ \\
\hline$P_{11}$ & D\# & $\mathrm{D}$ & $\mathrm{C \#}$ & C & A & $\mathbf{R}_{11}$ \\
\hline
\end{tabular}

\begin{tabular}{|c|c|c|c|c|c|c|}
\hline$I_{0}$ & E & $\mathrm{F}$ & F\# & G & A\# & $\mathrm{RI}_{0}$ \\
\hline $\mathrm{I}_{1}$ & $\mathrm{~F}$ & F\# & $\mathrm{G}$ & G\# & B & $\mathrm{RI}_{1}$ \\
\hline$I_{2}$ & $\mathrm{~F} \#$ & $\mathrm{G}$ & G\# & $A$ & C & $\mathrm{RI}_{2}$ \\
\hline $\mathrm{I}_{3}$ & G & $\mathrm{G} \#$ & A & A\# & $\mathrm{C \#}$ & $\mathrm{RI}_{3}$ \\
\hline $\mathrm{I}_{4}$ & G\# & A & A\# & B & $\mathrm{D}$ & $\mathrm{RI}_{4}$ \\
\hline$I_{5}$ & A & A\# & B & C & D\# & $\mathrm{RI}_{5}$ \\
\hline$I_{6}$ & A\# & B & C & C\# & $E$ & $\mathrm{RI}_{6}$ \\
\hline $\mathrm{I}_{7}$ & B & C & C\# & $\mathrm{D}$ & $\mathrm{F}$ & $\mathrm{RI}_{7}$ \\
\hline $\mathrm{I}_{8}$ & C & C\# & $D$ & D\# & F\# & $\mathrm{RI}_{8}$ \\
\hline$I_{9}$ & C\# & $\mathrm{D}$ & D\# & $\mathrm{E}$ & $\mathrm{G}$ & $\mathrm{RI}_{9}$ \\
\hline$I_{10}$ & $\mathrm{D}$ & $\mathrm{D \#}$ & $\mathrm{E}$ & $\mathrm{F}$ & G\# & $\mathbf{R I}_{10}$ \\
\hline$I_{11}$ & D\# & $\mathrm{E}$ & $\mathrm{F}$ & F\# & A & $\mathrm{RI}_{11}$ \\
\hline
\end{tabular}

\section{Ex.11 - Formas do motivo de cinco notas do Concerto para Piano e Orquestra N. ${ }^{\circ} 5$ de Camargo Guarnieri}

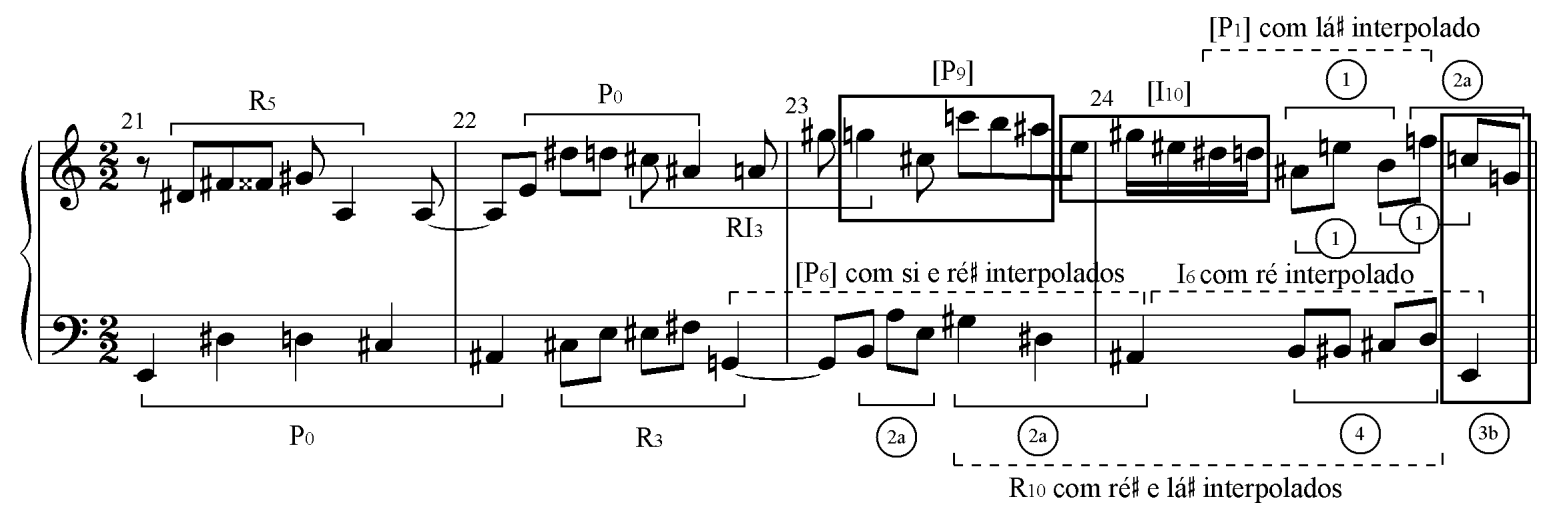

Ex.12 - Compassos iniciais do tema A (c.21-24) do Concerto para Piano e Orquestra N. 5 de Camargo Guarnieri 
altera sua inteligibilidade pela superposição das diferentes formas seriais. Esta característica será ainda mais marcante nos compassos seguintes do tema A (Ex.13).

Como se observa no Ex.13, os c.25-27 do tema A contêm vários tipos de sonoridade. 0 motivo gerador aparece apenas uma vez, mas de forma desordenada e com uma nota interpolada (c.26). Dois recursos contrapontísticos são utilizados brevemente nesta passagem. 0 primeiro é uma permutação de voz (voice exchange) envolvendo as classes de notas Láb e Fáb no c.25 (indicadas no Ex.13 com linha pontilhada). 0 segundo é uma imitação literal, no c. 26 , que é indicada com colchetes pontilhados e uma seta. Observase também uma similaridade de contorno entre o gesto indicado com um $x$ (c.25, mão direita) e o motivo gerador. ${ }^{9}$ Mais três compassos do tema A são mostrados no Ex.14.
A primeira sonoridade vertical é do Tipo 2b. A segunda sonoridade vertical é um composto de duas sonoridades do Tipo 1: Fá-Sib-Mi (mão direita) and Lá-Sib-Mi (mão direita e esquerda). Um ostinato, nos graves da mão esquerda, formado pela sonoridade do Tipo 4 permeia a passagem como um todo e se integra ao motivo gerador a partir de $\left[\mathrm{P}_{7}\right]$, nos dois últimos compassos. A nota com um asterisco em $P_{7}{ }^{\prime}$ deveria ser um Fá, para garantir o padrão do motivo gerador. Contudo, parece que Guarnieri está utilizando um tipo de apojatura em nível profundo, já que esta nota é ajustada para o valor "correto" logo em seguida, em $\left[\mathrm{P}_{7}\right]$. Os últimos cinco compassos do tema A são mostradas no Ex.15. Consistem basicamente na interação do Tipo 1 (mão direita) com o Tipo 4 (mão esquerda); 0 Tipo 4 aparece como uma linha cromática ascendente. A mão direita encerra o tema $A$ com o motivo gerador na forma de $\left[R_{5}\right] .{ }^{10}$

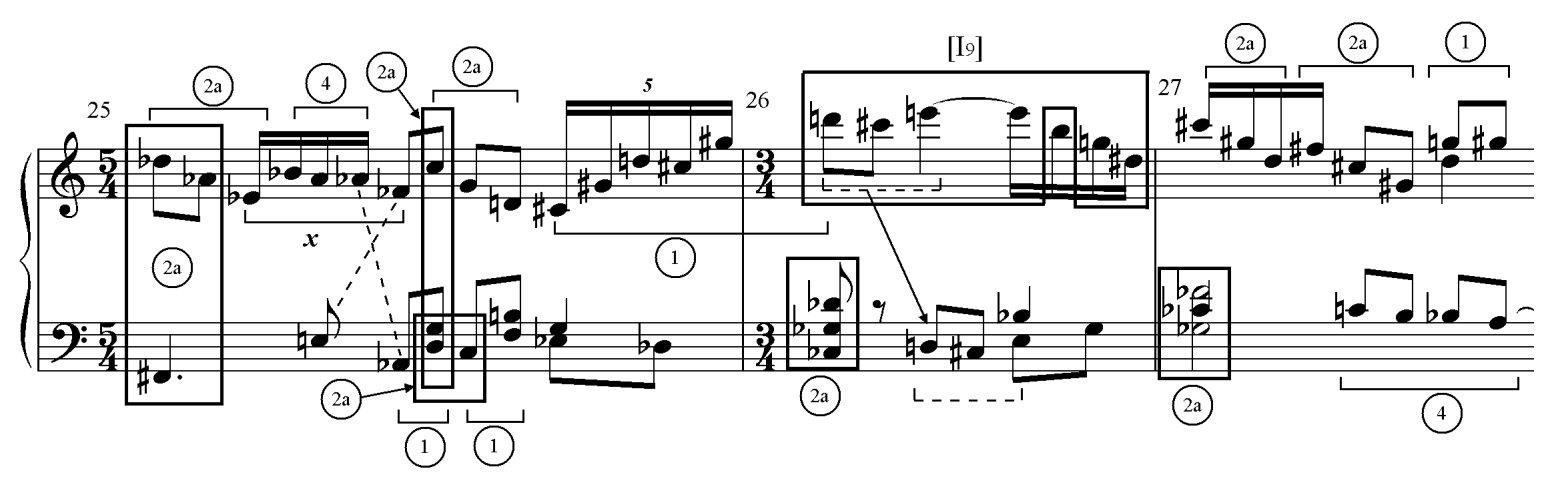

Ex.13. Trecho do tema A (c.25-27) do Concerto para Piano e Orquestra N. ${ }^{\circ} 5$ de Camargo Guarnieri

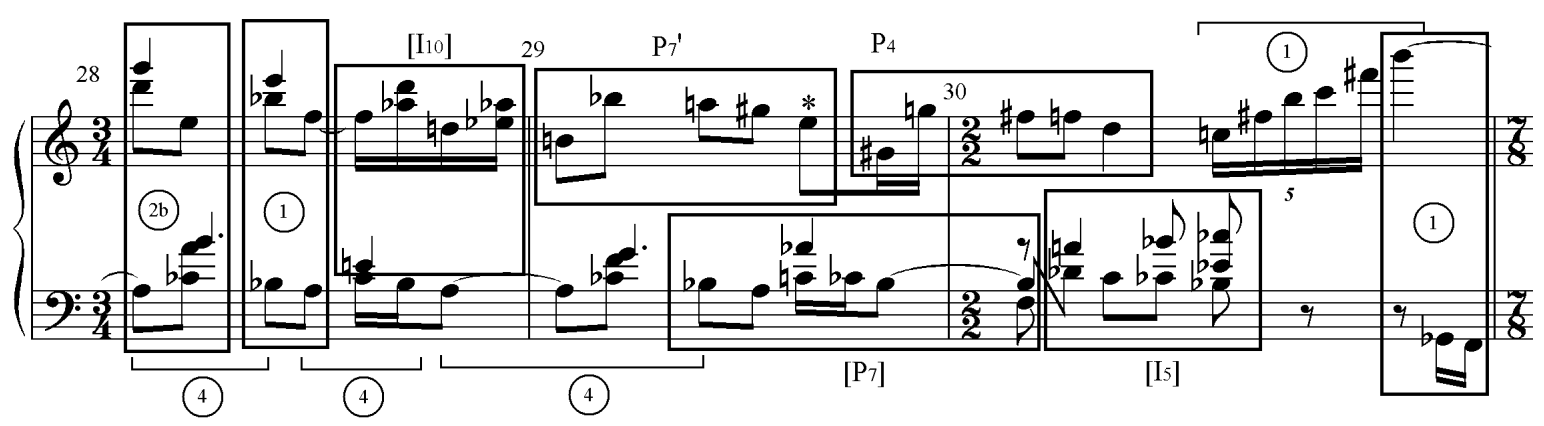

Ex.14 - Trecho do tema A (c.28-30) do Concerto para Piano e Orquestra N. ${ }^{\circ} 5$ de Camargo Guarnieri

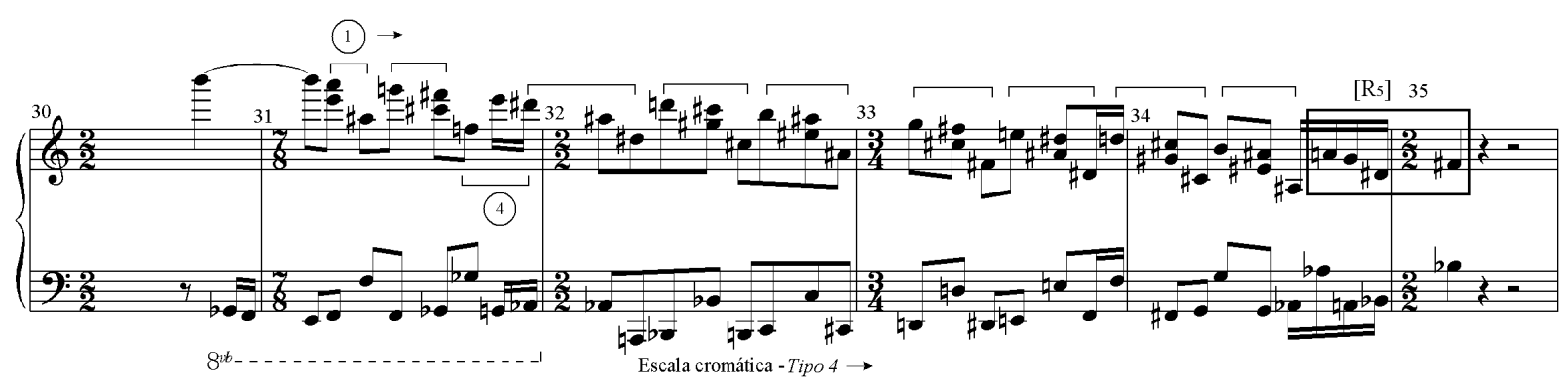

Ex.15 - Trecho do tema A (c.31-35) do Concerto para Piano e Orquestra N.o 5 de Camargo Guarnieri 
0 segundo grupo temático $(B)$, consiste de três temas: $B_{1}, B_{2}$ and $B_{3}$. $B_{1}$, um tema curto e sincopado (Ex.16), é construido a partir do motivo gerador e tem onze classesde-notas diferentes. $B_{2}$, executado pelos trombones (Ex.17), ${ }^{11}$ é inteiramente construído a partir da escala pentatônica (Solb-Láb-Sib-Réb-Mib) e, portanto, consiste na sonoridade do Tipo 2 (harmonia quartal). ${ }^{12}$ Concomitantemente à apresentação de $B_{2}$ pelos trombones, o piano executa um ostinato ornamental que consiste em segundas maiores e menores ${ }^{13}$ na mão direita, enquanto a mão esquerda, ao mesmo tempo em que complementa ritmicamente este ostinato, expressa a sonoridade Tipo 1. Esta figuração rítmica, introduzida pela primeira vez no acompanhamento de $B_{1}$ aparecerá diversas vezes na obra, combinada aos intervalos de segundas maiores e menores. ${ }^{14}$ No c. 50 , o terceiro tema $\left(B_{3}\right)$ do segundo grupo temático é introduzido pelo trompete com surdina (Ex.18). Observam-se as segundas ornamentais executadas pelo piano (mão direita). 0 trecho de $\mathrm{B}_{3}$ executado pelo trompete pode ser analisado como uma mistura do Tipo $2 b$ (Mi-RéSol-Si-(Sol\#) Lá) com trítonos (Dó\#-Sol, Si-Fá), exceto pelo Sol\#, que pode ser explicado como uma bordadura incompleta. ${ }^{15} 0$ trítono deriva do motivo gerador, como

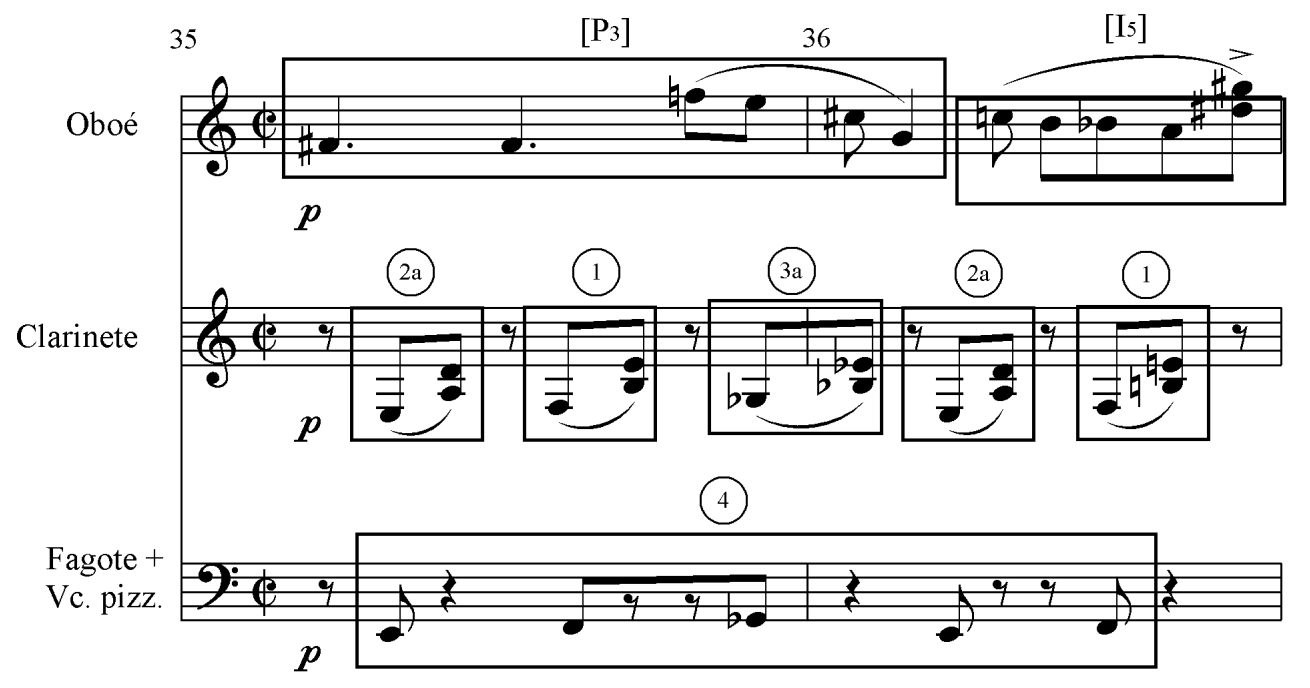

Ex.16 - Tema B1 (c.35-36) do Concerto para Piano e Orquestra N.o 5 de Camargo Guarnieri

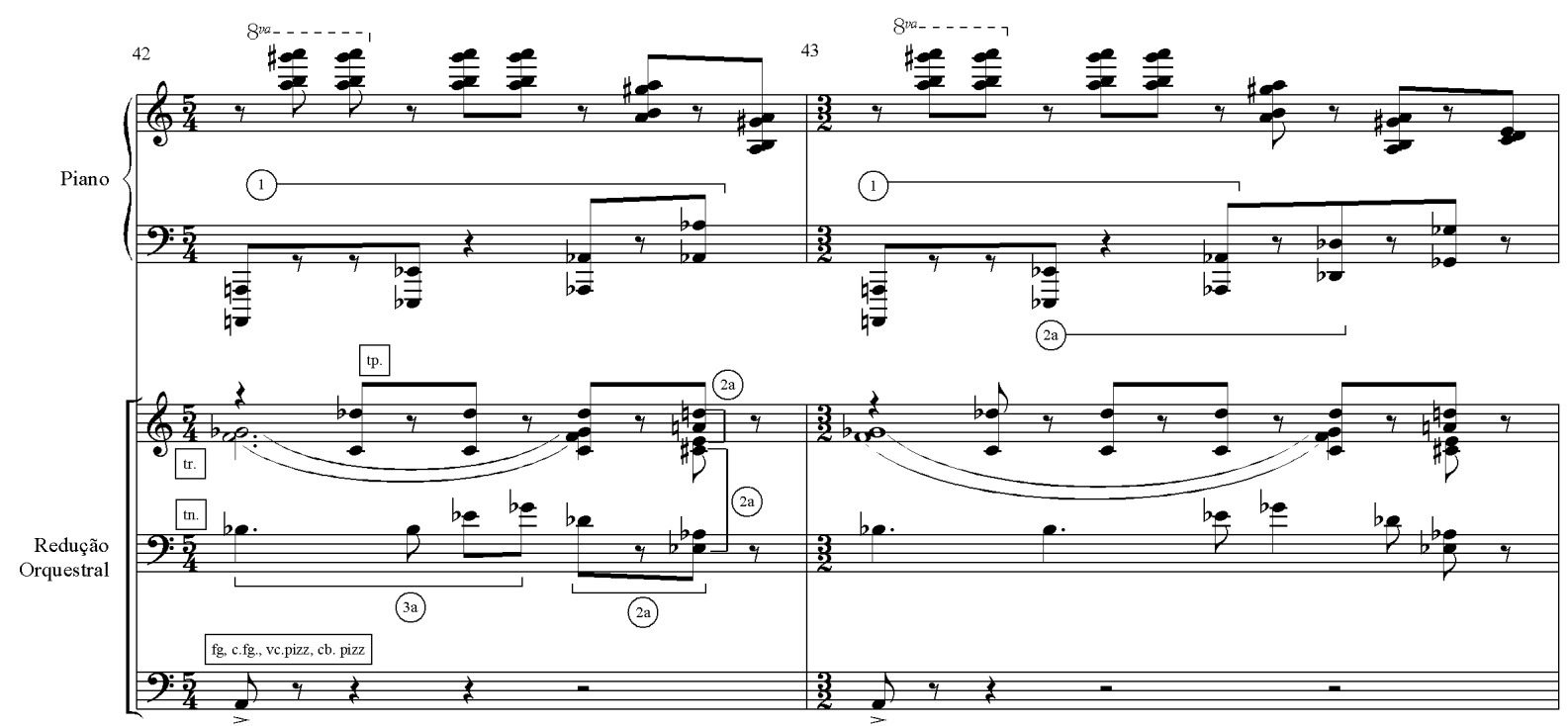

Ex.17 - Tema $B_{2}$ (c.42-43) do Concerto para Piano e Orquestra N. 5 de Camargo Guarnieri 
vimos anteriormente. Consequentemente, $B_{3}$ também é derivado do motivo gerador. 0 piano, além de dobrar a parte do trompete executa um acompanhamento que consiste verticalmente na sonoridade Tipo 4. Excluindose da mão direita a melodia do trompete, observa-se uma forma desordenada do motivo gerador, $\left[\mathrm{P}_{1}\right]$, enquanto a linha superior da mão esquerda consiste na sonoridade Tipo 2 (Ex.19).

\section{4 - Conclusão}

0 Ex.20 mostra a estrutura de todo o primeiro movimento do Concerto para Piano e Orquestra N. ${ }^{\circ} 5$ de Camargo Guarnieri. Embora no aspecto formal, esta obra tenha fortes conexões com a tradição (forma sonata), Guarnieri evidencia aqui uma sintonia com a composição sistêmica da segunda metade do século XX e um completo controle composicional de aspectos micro-estruturais, quando, de acordo com nossa modelagem, parte unicamente de um motivo gerador, o qual Ihe fornece as possibilidades de utilizar tanto o atonalismo desordenado - através das sonoridades que definimos - quanto um serialismo que é, algumas vezes ordenado e outras desordenado. ${ }^{16}$

Por último, observamos que, coincidentemente, o número cinco parece ter alguma significação numerológica nesta obra. Este é o quinto concerto de Guarnieri (cuja abertura se assemelha ao quinto concerto de Beethoven), que é construido a partir de um gesto de cinco notas, o qual gera cinco sonoridades básicas. 0 evento inicial da orquestra dura cinco compassos, aos quais se seguem blocos de arpejo, executados pelo piano, defasados por um intervalo de quinta justa. Um estudo que enfoque com profundidade esta conexão numerológica (como existe, por exemplo, no quinto Quarteto de Cordas de Bartók) pode revelar importantes facetas sistêmicas do serialista Camargo Guarnieri.

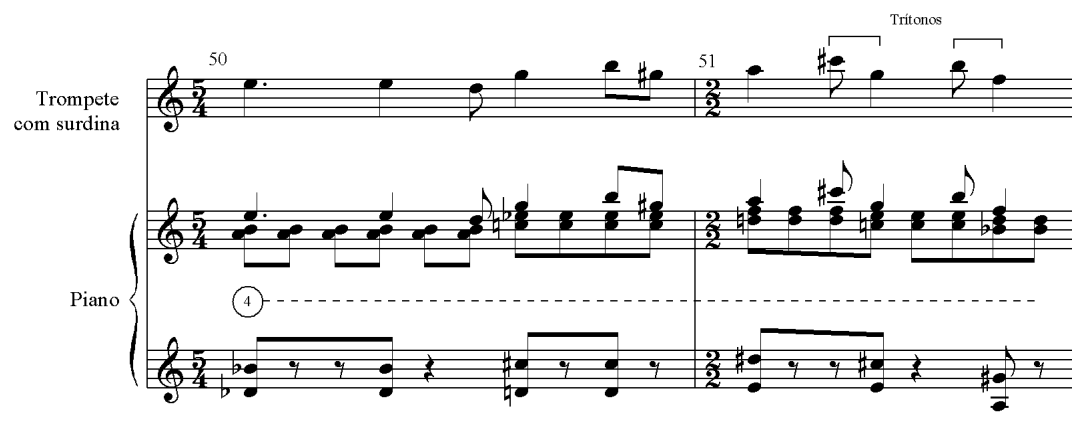

Ex.18 - Tema $B_{3}$ (c.50-51) do Concerto para Piano e Orquestra N. 5 de Camargo Guarnieri



Ex.19 - Acompanhamento do tema $B_{3}$ (c.50-51) do Concerto para Piano e Orquestra N. 5 de Camargo Guarnieri 


\begin{tabular}{|c|c|c|c|}
\hline & Seção & Compassos & Comentários \\
\hline \multirow{7}{*}{ EXP. } & \multirow{3}{*}{ Intro. } & $1-4$ & Tutti orquestral \\
\hline & & 5 & Piano: cadência \\
\hline & & $6-20$ & Cânon dos metais \\
\hline & A & $21-34$ & $\begin{array}{l}\text { Primeiro grupo: Primeiro tema (piano) } \\
\text { - A }\end{array}$ \\
\hline & \multirow{3}{*}{ B } & $35-36$ & $\begin{array}{l}\text { Segundo grupo: Tema } \mathbf{B}_{1} \\
\text { (Corne inglês) }\end{array}$ \\
\hline & & $42-49$ & Segundo grupo: Tema $\mathbf{B}_{2}$ (trombone) \\
\hline & & $50-51$ & $\begin{array}{l}\text { Segundo grupo: Tema } \mathbf{B}_{3} \\
\text { (piano + trompete) }\end{array}$ \\
\hline \multirow{4}{*}{ DES. } & & $56-81$ & Desenvolvendo $A$ e $B_{1}$ \\
\hline & & $82-100$ & $\mathbf{B}_{1}$ profundamente transformado \\
\hline & & $101-110$ & Desenvolvendo $\mathrm{A}$ \\
\hline & Retrans. & $111-126$ & Baseada na introdução \\
\hline \multirow{6}{*}{ RECAP. } & A & $127-140$ & Primeiro grupo: Tema $\mathbf{A}$ \\
\hline & \multirow{4}{*}{ B } & $141-142$ & Segundo grupo: Tema $\mathbf{B}_{1}$ \\
\hline & & $143-152$ & $\begin{array}{l}\text { Material baseado no acompanhamento } \\
\text { usado no tema } B_{2} \text { (c. } 42-49 \text { ) }\end{array}$ \\
\hline & & $152-154$ & Prato suspenso como conector \\
\hline & & $155-168$ & Retrógrado de $87-100$ \\
\hline & Coda & $173-190$ & Cânon + acorde sustentado. \\
\hline
\end{tabular}

Ex.20 - Estrutura do primeiro movimento do Concerto para Piano e Orquestra N. 5 de Camargo Guarnieri 


\section{Referências}

ALDWELL, Edward e Carl Schachter, Harmony and Voice Leading. New York: Harcourt Brace Jovanovich, 1989.

FORTE, Allen. The Structure of Atonal Music. New Haven: Yale University Press, 1973.

GUARNIERI, Camargo. Concerto para Piano e Orquestra No.5. Manuscrito do autor. São Paulo: [s.n], 1970. 1 partitura (75p.). Orquestra.

VERHAALEN, Marion. Camargo Guarnieri: Expressões de uma Vida. Trad. Vera Silvia Camargo Guarnieri. São Paulo: Editora da Universidade de São Paulo/ Imprensa Oficial, 2001.

Notas

1 Sua primeira obra sinfônica foi o Concerto para Piano e Orquestra N. 1 (1931), composto treze anos antes de sua Primeira Sinfonia.

2 Nas notas de programa sobre esta peça, o próprio Guarnieri menciona que o segundo movimento é monotemático e organizado em três partes: exposição, desenvolvimento e recapitulação. Marion Verhaalen rotula estas três partes ABA. Também de acordo com Guarnieri, o segundo movimento foi o primeiro a ser composto (VERHAALEN, 2001, p.230).

3 Por exemplo, o primeiro tema do segundo grupo temático (Ex.17), no primeiro movimento, consiste na justaposição de duas formas diferentes do motivo, cada uma com uma diferente ordenação de notas.

4 Estes princípios são os mesmos utilizados por Allen FORTE (1973) para conceituar classes-de-nota, termo que aliás também será utilizado neste artigo, quando necessário. Optamos por utilizar um sistema contendo apenas cinco sonoridades em virtude de ser mais compacto e, portanto, de fácil assimilação e visualização durante o processo analítico, e também por conter relações de similaridade, especialmente auditiva, não contempladas explicitamente nas classes de conjuntos de classes-de-notas de Allen Forte. Assim, nosso Tipo 1 abrange os tricordes 016 e o tetracorde 0167; todos os gestos cromáticos $(012,0123,01234, \ldots)$ são agrupados no Tipo 4 e as sonoridades quartais são agrupadas no Tipo 2.

5 Abreviatura dos instrumentos: pic=flautim, fl=flauta, ob=oboé, $\mathrm{cl}=\mathrm{clarinete}, \mathrm{vn}=\mathrm{violino}, \mathrm{c} . \mathrm{i}=\mathrm{corne}$ inglês, $\mathrm{tr}=\mathrm{trompa}, \mathrm{va}=\mathrm{viola}, \mathrm{fg}=\mathrm{fagote}, \mathrm{c} . \mathrm{fg}=$ contrafagote, tim=timpani, $v c=$ violoncelo, $c b=$ contrabaixo.

6 A idéia de introduzir o instrumento solista no início do concerto é fundamentada na tradição: foi utilizada por Mozart (Concerto N. 9 em Mi bemol maior, K271), Beethoven (Concerto N. 5 em Mi bemol maior, Opus 73, com o qual a abertura de Guarnieri parece ter certa semelhança textural) e, mais recentemente, por Schoenberg.

7 Encontramos paralelos deste processo no periodo tonal: temas levam tempo para se cristalizarem em obras tais como a Terceira Sinfonia e a Nona Sinfonia de Beethoven.

8 Obviamente, uma matriz $12 \times 12$ não pode ser utilizada neste caso, uma vez que a série contém somente cinco notas. Uma matriz $5 \times 5$ excluiria diversas classes-de-notas e, portanto, não refletiria a realidade da obra, uma vez que Guarnieri se utiliza de todo o espaço cromático.

9 Ambos os motivos iniciam na nota mais grave, movem-se ascendentemente para a nota mais aguda e descem gradualmente até alcançar a segunda nota mais grave. A linha descendente em ambos os motivos é cromática.

10 Fá\# do piano (mão direita, último compasso) é a mesma nota com que o oboé introduz o segundo tema do concerto.

11 Abreviatura dos metais: $\mathrm{t} p=$ trompete, $\mathrm{tr}=$ trompa, $\mathrm{tn}=$ trombone.

12 As notas de uma escala pentatônica podem ser facilmente arrumadas em quartas, preservando tanto a sonoridade pentatônica (pela pequena quantidade de notas), como criando harmonia quartal.

13 Segundas maiores e menores se relacionam diretamente com o motivo gerador. Se tomarmos uma das formas do motivo, por exemplo, Sol4-Fá\#5Fá5-Mi5-Dó\#5, observa-se que sua porção central (Fá\#5-Fá5-Mi5) é inteiramente construída a partir destes dois intervalos.

14 Esta caracteristica revela conexões com a música de Bartók (Out of Doors ou a Suite, por exemplo). Outra conexão Bartókiana seria o uso de harmonia quartal, amplamente utilizada no concerto de Guarnieri.

15 Bordaduras incompletas têm somente uma conexão conjunta com uma nota real (ALDWELL, 1989, p.316).

16 A rigor, o serialismo implica ordem. Porém, Guarnieri utiliza permutações livres do motivo gerador, como Hauer faz com os hexacordes de suas séries dodecafônicas, sem se preocupar com os postulados fundamentados pela Segunda Escola de Viena e mais tarde corroborados pelas vanguardas serialistas européias e norte-americanas.

Liduino Pitombeira é compositor com obras executadas pelo Quinteto de Sopros da Orquestra Filarmônica de Berlim, Orquestra Filarmônica de Poznan (Polônia) e Orquestra Sinfônica do Estado de São Paulo. Suas obras são publicadas pela Peters, Bella Musica, Filarmonika LLC, Cantus Quercus, Conners, Alry, RioArte, Criadores do Brasil (OSESP) e Irmãos Vitale. Pitombeira também vem tendo diversas obras gravadas regularmente desde 1997 pelos selos Magni, Summit, Centaur, Antes, Filarmonika e Bis, bem como por selos independentes. Atualmente, é professor adjunto de composição e teoria do Departamento de Música da Universidade Federal da Paraiba. 